\title{
LA RESPONSABILIDAD DEL ESTADO CHILENO POR HECHOS DE LA ADMINISTRACIÓN: AVANCES Y RETROCESOS
}

\author{
Mauricio Viñuela Hojas ${ }^{1}$
}

RESUMEN: El artículo expone la controversia acerca de los fundamentos de la construcción dogmática y jurisprudencial relativos a la Responsabilidad del Estado por bechos de la Administración. Atiende a una revisión especialmente enfocada desde la Constitución de 1980 y su legislación derivada; para luego realizar un análisis de la legislación y jurisprudencia reciente sobre la materia expuesta.

Palabras clave: Responsabilidad del Estado - Jurisprudencia - Violaciones a Derehos Humanos - Falta u Omisión de Servicio.

\section{Responsibility of the Chilean State on ADMINISTRATION DEEDS: PROGRESS AND REGRESSION}

ABSTRACT: The article exposes the controversy regarding the fundamentals of the dogmatic construction and of the relative jurisprudential related to the responsibility of the State for administration deeds. It especially deals with the review focused from the 1980 Constitution and its derived legislation to carry out bereon an analysis of the legislation and recent jurisprudence regarding the expounded affair.

KEY WORDS: Responsibility of the State - Jurisprudence Violations to Human Rights - Service Omission or Misdemeanor.

SUMARIO: 1) Un punto de partida. 2) Situación a partir de la Constitución de 1980 y de su legislación derivada. 3) Análisis de algunas tendencias de la legislación y de la jurisprudencia recientes. 4) Conclusión.

\section{I) UN PUNTO DE PARTIDA}

La jurisprudencia reciente en materia de responsabilidad del Estado por hechos de la Administración, con un marcado énfasis en las causas

\footnotetext{
Doctor en Derecho, Universidad de Navarra, España. Profesor de Derecho Administrativo, Universidad de los Andes (Chile), Correo electrónico: mvinuela@uandes.cl

Artículo recibido el 29 de abril de 2005. Aprobado por el Comité Editorial el 7 de junio de 2005.
} 
vinculadas a las lesiones a los derechos fundamentales ocurridas durante el gobierno militar, vuelve a plantearse, regresando con ello a un tópico casi obsesivo en nuestros jueces, y que había sido aparentemente superado en nuestro derecho nacional, la construcción de la responsabilidad del Estado sobre la base de las normas de responsabilidad extracontractual contenidas en nuestro Código $\mathrm{Civil}^{2}$.

Dicha realidad, sea por la tendencia natural de nuestros tribunales ordinarios de justicia, llamados a conocer y pronunciarse sobre las demandas interpuestas para reclamar la responsabilidad del Estado, de buscar el asidero legal que les sirva de fundamento a sus fallos ${ }^{3}$, como también, por la menos encomiable razón de encontrar alguna regla analógica que les permita limitar las expectativas de los actores aminorando de paso el interés de litigar en contra del fisco, ya sea en cuanto al tipo de daños que pueden demandar, o más todavía, en cuanto al tiempo en que deben hacer valer sus pretensiones ${ }^{4}$, se traduce, de hecho, en una auténtica regresión de nuestra jurisprudencia frente al afán del derecho administrativo nacional por afirmar la especial naturaleza de la responsabilidad estatal frente a otras clases de responsabilidades, en particular, para superar de una vez por todas la tentación de insertarla dentro de las categorías de la responsabilidad civil extracontractual, construida esta sobre bases totalmente diferentes de aquella.

En efecto, es en la noción elemental de garantía de los administrados de la intangibilidad de sus derechos frente a la acción de los agentes estatales, auténtico motivo y fundamento del derecho administrativo de nuestro tiempo, y como derivación de ello, en la necesidad de restituir

2 El caso "Domic con Fisco", con fallo de la Corte Suprema de fecha 15 de mayo de 2002, en recurso de casación en el fondo rol N ${ }^{\circ}$ 4753-2001, publicado en la Gaceta Jurídica $\mathrm{N}^{\circ} 263$, constituye un auténtico hito en este retorno a la aplicación del Código Civil en materia de responsabilidad por hechos de la Administración, prefigurado por otro fallo de la Corte Suprema, de 27 de noviembre de 2000, por casación en el fondo en "Aedo con Fisco", causa rol $N^{\circ} 852-2000$, en que había llegado a la misma conclusión respecto de la responsabilidad del Estado derivada de actos administrativos.

3 En Chile, al igual que en Argentina, el régimen de responsabilidad del Estado ha sido desarrollado por la jurisprudencia más que por la vía legislativa, con la particularidad de que en el caso chileno no existen tribunales de lo contencioso administrativo, aceptándose en forma unánime que corresponde a los tribunales ordinarios el conocimiento de tales causas.

4 En esta línea más interesada del problema se entiende la posíción oficial del Consejo de Defensa del Estado de Chile, sustentada en diversos artículos difundidos en la Revista de Derecho editada por tal organismo. Cfr. Gonzalo Vial Correa, "El Estado Paga", en Revista de Derecho del CDE, No 2, 2000, pp. 9-11; Raúl Letelier Wartenberg, "Un estudio de efectos en las características de la responsabilidad extracontractual del Estado", en Revista de Derecho del CDE, $\mathrm{N}^{\circ}$ 6, 2002, pp. 149-187; Clara Szczaranzki Cerda, "Responsabilidad extracontractual del Estado", en Revista de Derecho del CDE, N8, 2002, pp. 11-42; y Pedro Pierry Arrau, "Prescripción de la responsabilidad extracontractual del Estado. Situación actual de la jurisprudencia de la Corte Suprema", en Revista de Derecho del CDE, $\mathrm{N}^{\circ} 10$, pp, 9-24; y en "¿Es objetiva la responsabilidad del Estado? Estado actual de la jurisprudencia", en Revista de Derecho del CDE, $\mathrm{N}^{\circ} 11$, pp. 11-19. 
todo desequilibrio que se ocasione a una víctima que sufre un daño en sus derechos por la acción u omisión antijurídica del Estado, donde se ha ido afianzando, paulatinamente, la teoría de la responsabilidad estatal objetiva y de derecho público, superando con ello, ya en términos prácticamente universales ${ }^{5}$, la construcción de una responsabilidad sustentada en las nociones subjetivas (moralistas) del derecho civil, que resultan incompatibles con el propósito de instaurar un mecanismo que sirva de real garantía y protección para los administrados, que no les imponga la carga de identificar al eventual funcionario público causante del daño, ni mucho menos probar la intencionalidad con que él actuó ${ }^{\text {, }}$

5 El carácter objetivo y la sujeción a de la responsabilidad del Estado a normas propias, diversas de las normas de responsabilidad civil, es hoy día una regla generalmente aceptada, como hacen ver en España, entre otros, Eduardo GARCía DE EnTERría y Tomás-Ramón Fernández, en Curso de Derecho Administrativo, t. II, $4^{a}$ ed., Civitas, Madrid, 1994, pp. 370 y ss.; Ramón Parada, Derecho Administrativo, t. I, $9^{a}$ ed, Marcial Pons, Madrid, 1997, pp. 675 y ss.; Francisco GonZález Navarro, Derecho Administrativo Español, t. I, $2^{\mathrm{a}}$ ed., Eunsa, Pamplona, 1995, pp. 246-248; Juan Alfonso Santamaría Pastor, Principios de Derecho Administrativo, t. II, $2^{a}$ ed., Ed. Centro de Estudios Ramón Areces, Madrid, 2001, pp. 471-479. Lo mismo ocurre también en Argentina, cfr. Juan Carlos CASSAGNE, Derecho Administrativo, c, I, $6^{a}$ ed., Abeledo-Perror, Buenos Aires, 2000, pp. 196-198 y 267-271.

6 Cfr. Eduardo Soto Kloss, Derecho Administrativo: Bases fundamentales, tomo II, Edit. Jurídica de Chile, Santiago de Chile, 1996, pp. 263-311, y antes, en "Bases para una teoría general de la responsabilidad extracontractual del Estado en el derecho chileno", en Revista de Derecho y Jurisprudencia, t. 81, 1984, $1^{\text {a }}$ parte, pp. 87-96. Entre otros autores que en el medio nacional avalan la comprensión de la responsabilidad del Estado con criterios de derecho público, y fuera de la órbita del ordenamiento civil, puede consultarse: Gustavo Fiamma Olivares, "La acción constitucional de responsabilidad y la responsabilidad por falta de servicio", en Revista Cbilena de Derecho, vol. 16, N², 1989, pp. 429-440; Hugo Caldera Delgado, Tratado de Derecho Administrativo, tomo I, Ediciones Parlamento, Santiago de Chile, 2001, pp. 230-231; de igual autor Sistema de la responsabilidad extracontractual del Estado en la Constitución de 1980, Ed. Jurídica de Chile, Santiago, 1983. Vid. también, Enrique Silva Cimma, Derecho Administrativo cbileno y comparado: Principios fundamentales del derecho público y Estado solidario, $1^{4}$ ed., Ed. Jurídica de Chile, Santiago, 1996, pp. 159-174; Rolando Pantoja BauzÁ, Bases generales de la Administración del Estado, Ed. Jurídica ConoSur, Santiago, 1997, p. 43; Patricio AYLwin Azócar y Eduardo Azócar Brunner, Derecho Administrativo, Ed. Universidad Andrés Bello, Santiago, 1996, pp. 137-141. En una posición algo distinta, vid. Osvaldo Oelckers Camus, para quien la Ley 18.575 objetiviza la responsabilidad de la Administración, pero ello no se traduce en establecer una responsabilidad objetiva que releve de la exigencia de probar la existencia de la falta de servicio o de la falta personal que causan el daño. Cfr. "La responsabilidad extracontractual del Estado administrador en las leyes orgánicas constitucionales de Administración del Estado y de Municipalidades", en Revista Chilena de Derecho, vol. 16, N ${ }^{\circ} 2$, 1989, pp. 441-454. Acorde con la jurisprudencia más actual, así como con la posición del Consejo de Defensa del Estado (vid. nota $\mathrm{N}^{\circ} 3$ ), las monografías más recientes sobre el tema reniegan abiertamente de la existencia de una diferencia entre la responsabilidad del Estado y la responsabilidad del código civil, estableciendo que ambas se construyen sobre la base de una negligencia objetivizada, esto es, que no se apela a la intencionalidad del agente público o privado que actúe sino a la comparación de la conducta u omisión con el patrón general y abstracto de conducta que establece la norma. Cfr. Luis Cordero VEGA, La responsabilidad de la Administración del Estado, LexisNexis, Santiago, 2003, pp. 
lo que es viable solamente si se establece una responsabilidad de base objetiva.

El camino del derecho nacional, hasta ahora, no parecía ser muy distinto en esta materia a la evolución que han seguido los demás países. Sin embargo, la realidad actual, sea por efecto de sentencias recientes de nuestro máximo tribunal, como también por alguna legislación que induce a confusión, no acaba de demostrar que los juristas chilenos hayamos entendido, de una vez por todas, que un genuino Estado de derecho requiere superar los tiempos de entender la responsabilidad estatal apelando a las categorías civiles de responsabilidad por delitos o cuasidelitos cometidos por los agentes de la administración, bajo la analogía de que estarían bajo el cuidado del Estado ${ }^{7}$, o que serían criados o sirvientes suyos ${ }^{8}$, fuentes normativas que, sin eufemismos, la mayor parte de las veces han sido usadas por la defensa judicial fiscal, y aceptadas por los tribunales, más bien para dar sustento a la irresponsabilidad que a la responsabilidad patrimonial estatal, generando con ello una vía práctica para un trasnochado y preconstitucional privilegio de irresponsabilidad de los poderes públicos.

Sea que nos remontemos al año 1938, caso "Granja con Fisco"9, que sentó en nuestro sistema el pernicioso criterio de la distinción entre actos de autoridad y actos de gestión de la Administración, aceptando para los segundos la aplicación de las normas civiles sobre responsabilidad, pero rechazándolas para los primeros, lo que supuso por varias décadas, a falta de normas legales especiales aplicables a la materia, asentar la total irresponsabilidad estatal por los actos de autoridad; o bien que vayamos al año 1964, caso "Becker con Fisco"10, a partir del cual la jurisprudencia impondrá el criterio conforme al cual la responsabilidad del Estado solo puede darse si previamente se ha comprobado el actuar antijurídico de uno de sus agentes que, según el caso, exigirá a la víctima probar el dolo o la culpa del funcionario causante del daño, es absolutamente evidente que, respecto de ambos hitos judiciales, la Constitución de 1980 supuso un cambio radical.

En contraste con los precedentes judiciales referidos, a partir de la Constitución de 1980 se fue abriendo paso, tanto en la doctrina como en la jurisprudencia chilenas, una forma de concebir la responsabilidad del Estado que, devolviéndole su sentido natural de garantía para los administrados a no ser lesionados en sus derechos como consecuencia del funcio-

160-172. Por su parte, Sanhueza Acosta rechaza categóricamente el carácter objetivo y el fundamento de derecho público de la responsabilidad del Estado, cfr. Ricardo SANHUEZA Acosta, Responsabilidad patrimonial del Estado, LexisNexis, Santiago, 2005, pp. 122-140.

Cfr. artículo 2320 del código civil.

Cfr. artículo 2322 del código civil.

Cfr. Revista de Derecho y Jurisprudencia, tomo 36, 1939, II, 1ª 227-283.

10 Cfr. Revista de Derecho y Jurisprudencia, tomo 62, 1965, II, 1", 6-13. 
namiento de los órganos de la Administración, recobraba su fundamento en las normas de derecho público que rigen la actuación de los poderes del Estado, a la vez que se apartaba de las normas del derecho privado.

Quedaba así asentaba la noción, históricamente consistente con nuestra evolución institucional republicana, conforme a la cual la responsabilidad del Estado es el efecto jurídico dado por la Constitución a los actos, hechos, conductas u omisiones contrarios a Derecho producidos por un órgano del Estado en el ejercicio de sus funciones y que ocasionan daño a una víctima que no está jurídicamente obligada a soportarlo ${ }^{11}$.

Volvía también nuestra jurisprudencia a reconocer la fuente de la responsabilidad del Estado en la propia Constitución Política ${ }^{12}$, a falta de otras leyes especiales dictadas a tal efecto, como ocurrió con total normalidad durante la vigencia de la Constitución de $1833^{13}$ hasta la aparición del tristemente célebre artículo 87 de la Constitución de 1925 , junto a todos los desaciertos judiciales a que dicha disposición dio lugar, y que abrieron cauce a toda suerte de construcciones de la doctrina nacional que llevaron a asentar como regla general la exención de control judicial de la actividad administrativa, a la vez que una natural irresponsabilidad del Estado, a menos que existiera una ley expresa que la estableciera, como erradamente se pensó que ocurría con el Código Civil, en cuanto ley aplicable a aquella actividad del Estado denominada "de gestión", en que se entendía que este actuaba como un particular más.

Esta primera realidad aplicativa de la Constitución de 1980, llevó a afirmar como características de la responsabilidad estatal las siguientes:

- responsabilidad de carácter constitucional, esto es, no civil;

- de la persona jurídica estatal y no de las personas naturales que actúan a su nombre;

- de base objetiva, esto es, que no exige la comprobación de dolo o culpa por parte del agente público sino la sola relación de causalidad entre el daño y la acción u omisión antijurídica;

11 Cfr. Eduardo Soto KLoss, Derecho Administrativo... op. cit., pp. 307-308. También la misma idea del daño antijurídico se encuentra en José Ignacio Martínez Estay, "La responsabilidad patrimonial del Estado por infracción al principio de igualdad y al derecho de propiedad en el derecho público chileno", en AA.Vv., Derecho de Daños, Ed. ConoSur LexisNexis, Santiago, 2002, p. 185.

12 Por primera vez desde la vigencia de la Constitución de 1980 en "Comunidad Galletué con Fisco", considerando $9^{\circ}$, sentencia de la Corte Suprema del 7 de agosto de 1984, en casación de fondo. En Revista de Derecho y Jurisprudencia, tomo 81, 1984, II, 5a , 181-189.

13 Sobre el particular vid. comentarios de Eduardo Soto KLoss a fallos de "Sociedad Fuschs y Plarh con Fisco" (año 1908) y "Lapostol con Fisco" (año 1930), en Derecho Administrativo... op. cit., pp. 280-292; y 390-397. 
- directa, de la persona jurídica y no indirecta, por el hecho de un tercero;

- regida por el derecho público y no por el derecho civil; e

- integral o total, en cuanto exige la reparación de todo daño ocasionado a la víctima ${ }^{14}$.

A tales características principales pronto se sumaría, como nota extraída de la práctica judicial más que de la doctrina, el atributo de la imprescriptibilidad ${ }^{15}$ de la responsabilidad del Estado, como derivación de igual característica predicada respecto de la nulidad de derecho público que consagra el artículo $7^{\circ}$ inciso $3^{\circ}$ de nuestra Carta Fundamental, y a falta de norma expresa que estableciera la extinción de la responsabilidad estatal por el transcurso del tiempo.

Veremos hasta qué punto las ya referidas características se pueden afirmar hoy en día a la luz de la jurisprudencia reciente así como de cierta legislación que ha ido apareciendo en los últimos años. Valga como introducción para ilustrar el estado actual de las cosas, el fallo de la Corte Suprema en "Rebolledo Rojas con Fisco"16, en cuyo considerando $4^{\circ}$ se afirma, con bien poco acierto en realidad, ya que tal aseveración no es para nada consistente con jurisprudencia anterior y coetánea:

\section{"Que esta Corte ba sostenido reiteradamente que el artículo 38 de la Constitución Política de la República no consagra la responsabilidad objetiva del Estado".}

Al final del mismo considerando, tal vez intentado explicar en qué sentido dicha responsabilidad no sería objetiva, prosigue:

14 Cfr. Eduardo Soto KLoss, Derecho Administrativo... op. cit., pp. 308-311.

15 Vid. en caso "Hexagón con Fisco", en Revista de Derecho y Jurisprudencia, tomo 84, 1987, II, $5^{\mathrm{a}}, 217-232$. Luego, en forma más generalizada, en las demandas de nulidad de derecho público por casos de aplicación del Decreto Ley $\mathrm{N}^{\circ} 77$ de 1973 al patrimonio de personas naturales, donde se entiende que la imprescriptibilidad de la nulidad de derecho público se traduce, necesariamente, en igual efecto respecto de la acción de responsabilidad del Estado. Así, entre otros, "Teitelboim Volosky con Fisco" (1990), causa rol N 4200-90, de la Corte de Apelaciones de Santiago, cfr. Eduardo Soto Kloss, Derecho Administrativo... op. cit., pp. 229-236; "Pérsico con Fisco" (1997), fallo de la Corte Suprema en casación de fondo, en Revista de Derecho y Jurisprudencia, tomo 94, año 1997, II, 1a, pp. 126-128; también en "Bussi con Fisco" (1998), en Fallos del Mes N ${ }^{\circ} 476$, pp. 1022-1034. El cambio de criterio en la jurisprudencia de la Corte Suprema comienza con "Aedo con Fisco", en el fallo de la Corte Suprema del 27 de noviembre de 2000, en recurso de casación rol 852-2000, en que se comienza a separar entre la imprescriptibilidad de la acción de nulidad de derecho público y la prescripción de los efectos patrimoniales que derivan del acto nulo.

16 Sentencia de la Corte Suprema del 29.09.2004 en casación de fondo Rol 2046-2003. 
"Se ha dicho, también, que en el ordenamiento jurídico patrio, por regla general, no existe una responsabilidad estatal objetiva, por cuanto solo las actuaciones que merecieran reproche por causar injustamente un daño o por haberse ejecutado de manera arbitraria, podrían traer consigo una reparación patrimonial, en la medida que sean objeto de algún reparo de ilegitimidad".

Pero el desacierto judicial del fallo no acaba ahí, ya que en el considerando $5^{\circ}$, redondeará el razonamiento descartando la existencia de una responsabilidad estatal constitucional, orgánica y objetiva, todo ello para poder llegar, sin mayores obstáculos, a afirmar que es plenamente aplicable a dicha responsabilidad la norma represcripción establecida en el Código Civil.

Esta auténtica dicotomía en materia de responsabilidad del Estado que se aprecia en las decisiones judiciales, donde se advierte no solo una contradicción entre el presente y el pasado reciente, sino una total asimetría entre la forma benevolente de tratar la responsabilidad estatal frente a otros tipos de responsabilidades ${ }^{17}$, y junto a ello una absoluta falta de unidad y sistematización legislativa del régimen de responsabilidad estatal son, a mi parecer, las características más importantes que en esta materia se advierten en la realidad actual del derecho chileno.

\section{2) Situación a partir de la Constitución de i980 y de su LEGISLACIÓN DERIVADA}

Se suele citar que, después del inicio de la vigencia de la Constitución de 1980, la primera vez que nuestros tribunales aceptaron que la responsabilidad estatal tenía su fuente y origen en la Constitución y que, por lo mismo, no se sujetaba a las normas del Código Civil, fue en el caso "Hexagón Ltda. Sociedad Importadora con Fisco"18, en fallo de la Corte Suprema de julio de 1987. Se trató de una auténtica novedad en su época, que poco tenía de novedoso si se tiene en cuenta que, en el fondo, suponía una regresión a las ideas matrices de la res-

17 Tal vez el ejemplo más llamativo de esto es la jurisprudencia en materia de responsabilidad penal por casos de detenidos desaparecidos durante el gobierno militar, que ha admitido la ficción del secuestro permanente con el fin deliberado de sortear la prescripción de las acciones por delitos de homicidio cometidos por agentes estatales. Otros ejemplos que evidencian esta falta de consistencia en el tratamiento de la responsabilidad se advierte en el énfasis puesto en ciertas clases de responsabilidad vinculadas a la protección de derechos sociales o intereses colectivos, por ejemplo, la impuesta a los empleadores en la legislación laboral, o la responsabilidad de los prestadores de bienes y servicios establecida en la legislación de protección al consumidor, entre otras.

18 Revista de Derecho y Jurisprudencia, tomo 84, 1987, II, 5*, 217-232. 
ponsabilidad del Estado, tal y como había sido ella tratada en nuestra jurisprudencia anterior a la Constitución de 1925.

Al texto constitucional, se había añadido ya, desde 1986, la ley orgánica constitucional de bases Generales de la Administración del Estado ${ }^{19}$, cuya dictación ordenaba el art. 38 de la Constitución, y que en sendos artículos $4^{\circ}$ y $44^{\circ}$ establecía:

Artículo 40: "El Estado será responsable por los daños que causen los órganos de la Administración en el ejercicio de sus funciones, sin perjuicio de las responsabilidades que pudieren afectar al funcionario que los bubiere ocasionado".

Artículo 44: "Los órganos de la Administración serán responsables del daño que causen por falta de servicio.

No obstante, el Estado tendrá derecho a repetir en contra del funcionario que bubiere incurrido en falta personal"20.

Características notables de estas disposiciones son la no referencia a un plazo de prescripción, a la vez que la ausencia de las más elementales reglas sustantivas en cuanto al tipo de daño indemnizable y a las condiciones procesales para la procedencia del mismo. A falta de dicha regulación positiva, obviamente la labor de interpretación y de integración que ha correspondido a los tribunales ha sido de vital importancia.

En claro contraste con esto, poco antes, se había dictado la ley orgánica constitucional de los Estados de Excepción ${ }^{21}$, que desarrollando las disposiciones constitucionales pertinentes disponía que las requisiciones y demás limitaciones que se impusieran al derecho de propiedad darán lugar a la indemnización de los perjuicios directos en contra del Fisco. Al efecto, estableció que el monto de la indemnización y la forma de pago serían determinados de común acuerdo y, a falta de tal acuerdo, por el juez de letras competente, caso en que la indemnización debería pagarse en dinero efectivo y al contado. En cuanto a la procedencia de la acción indemnizatoria, el legislador concedió un escueto plazo de 1 año contado desde la fecha de conclusión del estado de excepción.

Un par de años después, otra vez por ley orgánica constitucional, esta vez de Municipalidades $^{22}$, el legislador derogaba la norma de la

Ley 18.575, Diario Oficial del 5.12.1986.

20 Artículo 42, según numeración contenida en el texto refundido de la ley, fijado por el DFL No1/19.653, de 2000.

21 Ley 18.415 del año 1985 . Vid artículos 17,19 y 20.

22 Ley 18.695, Diario Oficial del 31 de marzo de 1988. 
legislación anterior que vinculaba la responsabilidad de estas corporaciones al código civil, incluso distinguiendo entre responsabilidad contractual y extracontractual ${ }^{23}$, suprimiendo el brevísimo plazo de prescripción que igualmente se establecía ${ }^{24}$ y, fijando en lugar de todo ello, una regla mucho más general, consecuente con el artículo 38 inciso $2^{\circ}$ de la Constitución, conforme a la cual:

\section{"Las municipalidades incurrirán en responsabilidad por los daños que causen, la que procederá principalmente por falta de servicio. No obstante, las municipalidades tendrán derecho a repetir en contra del funcionario que bubiere incurrido en falta personal" 25 .}

Coincidiendo con el retorno del país a la democracia, comienza una virtual avalancha de demandas de indemnización dirigidas en contra del Estado por casos de violación de derechos humanos y por actos dañosos emitidos durante el gobierno militar. En un comienzo, siguiendo la línea jurisprudencial que establecía el carácter constitucional de la responsabilidad, nuestros tribunales tuvieron una disposición favorable a aceptar el carácter objetivo de dicha responsabilidad, relevando a la víctima de la obligación de demostrar dolo o culpa en el funcionario causante del perjuicio, y afirmando, no pocas veces, la imprescriptibilidad de dicha responsabilidad, en el entendido que no siendo aplicable la norma de prescripción prevista en el Código Civil, y no existiendo norma especial de derecho público al efecto, solo cabía concluir la voluntad del legislador en orden a no aceptar dicha prescripción ${ }^{26}$.

De ese período es una larga secuela de sentencias que acogieron demandas interpuestas por víctimas de requisiciones de bienes personales suyos, efectuadas en aplicación del Decreto Ley $\mathrm{N}^{\circ} 77$ que, aceptando el carácter imprescriptible de la nulidad constitucional de los actos estatales contrarios a derecho, aceptaban también la imprescriptibilidad de los efectos patrimoniales que de dicha nulidad se derivan, una vez constatada judicialmente la existencia de la misma.

23 Decreto Ley 1289 (1975), artículo 62.

24 Artículo 63 del DL 1289, las acciones para hacer efectiva (entre otras) la responsabilidad extracontractual de la Municipalidad prescribirá en el plazo de 1 año contado desde la fecha en que se produjo el perjuicio.

25 Art. 141 ley 18.695.

26 Vid. "Pérsico París con Fisco", sentencia de casación de fondo de la Corte Suprema de 20.11.1997, en Revista de Derecbo y Jurisprudencia, tomo 94, 1997, II, 1a , pp. 126-128. En el considerando $4^{\circ}$, se establece expresamente que no son aplicables las normas del derecho común tratándose de la responsabilidad que emana de una nulidad de derecho público, para efectos de configurar la prescripción de la acción. 
Desde ese momento, el único cambio legislativo más relevante a mencionar, se produjo en el contexto de una modificación a la Ley 18.575, durante la tramitación de la denominada Ley de Probidad Administrativa $^{27}$, y que formaba parte de un conjunto de iniciativas tendientes a dar mayor transparencia a la actividad administrativa. En el trámite de discusión y aprobación de esa ley, el Senado acordó eliminar el artículo 44 de la ley, aprobando una nueva redacción del artículo $4^{\circ}$, que era más acorde al artículo 38 inciso $2^{\circ}$ de la Constitución.

A su turno, la Cámara de Diputados, después de oír a los profesores Pedro Pierry y Rolando Pantoja, rechazó las enmiendas aprobadas por el Senado. Al hacerlo, se fundamenta que la razón de ser del artículo 44 de la Ley 18.575, ha sido establecer que el Estado no responde en forma objetiva, esto es, por el solo hecho de causar un daño, sino únicamente en cuanto hay una falta de su parte, ya sea una falta de servicio o una falta personal del funcionario 28 .

Finalmente, el Presidente de la República hace uso de un veto supresivo que es aprobado por el Congreso, en orden a excluir la modificación propuesta a los artículos $4^{\circ}$ y $44^{\circ}$, afirmando que la norma del art. 38 inciso $2^{\circ}$ de la Constitución solo establece una regla de competencia de los tribunales ordinarios para conocer del contencioso de reparación, pero no una regla sustantiva que establezca la responsabilidad objetiva ${ }^{29}$.

El problema, como quedó reflejado en actas, se origina por el error de haberse entendido por algunos que el carácter objetivo de la responsabilidad del Estado evitaría la necesidad de que la actuación estatal causante del daño debiera ser antijurídica. Bajo ese punto de vista, como sostiene el profesor Pierry, es claro que el sistema de responsabilidad extracontractual del Estado chileno se basa en la necesidad de una conducta antijurídica ${ }^{30}$, lo que necesariamente no se contrapone a una responsabilidad objetiva.

Si no cabe prescindir del carácter antijurídico de la actuación estatal para configurar su responsabilidad por los daños causados, tampoco cabe entender que la responsabilidad del Estado sea de orden subjetivo y, por lo mismo, que exija poder demostrar que la acción u omisión dañosa se ha debido a un proceder doloso o negligente de un funcionario público dado.

La cuestión más grave que puso en evidencia la discusión de la Ley 19.653 , reside en que el punto de vista que primó en el debate fue

Ley 19.653, publicada en el Diario Oficial del 14 de diciembre de 1999.

Cfr. Ricardo Sanhueza Acosta, Responsabilidad patrimonial... Op. cit., pp. 162-163.

Cfr. Idem, pp. 164-165.

Cfr. Pedro Pierry Arrau, "La responsabilidad extracontractual del estado por falta de servicio", en Revista de Derecho del CDE, No 1,2000 , pp. 17-27. 
el de evitar la ampliación de los supuestos de responsabilidad estatal, ante el peligro que se advertía de una objetivación absoluta de dicha responsabilidad, dejando postergados a un absoluto segundo plano los derechos e intereses de los administrados ${ }^{31}$. En su lugar, el legislador optó por mantener un sistema que favorece la imprecisión de conceptos y que, en consecuencia, permite a la defensa fiscal un uso analógico amplio del derecho civil para efectos de reducir la responsabilidad.

Resulta curioso, entre otros aspectos, que si el legislador pudo en esa ocasión, como ha podido hacerlo en todo tiempo, establecer una regla expresa de prescripción de la responsabilidad del Estado, así como la remisión de esta materia a las normas del derecho común, persista, no obstante, en dejar el tema entregado a la interpretación de los jueces. Tratándose de una cuestión tan básica de la regulación del Estado de Derecho parece, por lo menos, inconveniente que nuestro legislador lo haya dejado a la aplicación supletoria de normas del derecho común.

La situación posterior a dicha ley, básicamente constatada por el estudio de la jurisprudencia de los años posteriores, ha ido produciendo un nuevo retorno a las categorías de la legislación civil, básicamente en lo que dice relación con la aplicación supletoria de las normas de responsabilidad extracontractual y, en especial, para sustentar la prescripción extintiva de la misma.

Otro tanto cabe decir, con relación a la mantención del carácter objetivo de la responsabilidad estatal, cada vez más condicionado a la posibilidad de poder demostrar por parte de la víctima la existencia de una actuación antijurídica imputable a un agente de la administración, o imputable en general a la administración.

Junto a lo anterior, y enfrentados a un mismo escenario de mayor cantidad de litigios dirigidos en contra de organismos administrativos, el legislador no se ha quedado impasible.

Si bien sigue siendo válido afirmar que en Chile no hay una ley general reguladora de la responsabilidad del Estado ${ }^{32}$, a lo menos no

31 No obstante nuestra Constitución Política en su art. $1^{\circ}$ inciso $4^{\circ}$ establece con toda claridad que el Estado está al servicio de la persona humana y no al revés. Y acto seguido dispone que la finalidad del Estado es promover el bien común, para lo cual debe contribuir a crear las condiciones sociales que permitan a todos y cada uno de los integrantes de la comunidad nacional su mayor realización espiritual y material posible, con pleno respeto a los derechos que la Constitución establece.

32 El contraste con otros ordenamientos a este respecto es bien evidente. Por ejemplo, la ley 30/1992 española, de Régimen Jurídico de las Administraciones Públicas y Procedimiento Administrativo Común, contempla un capítulo especial (artículos 139-144), dedicado a regular la responsabilidad patrimonial de la Administración Pública, estableciendo las condiciones de procedencia de la misma, así como de su exclusión, los procedimientos aplicables para su determinación, las formas de reparación, el plazo de prescripción del derecho a reclamar, entre otros aspectos. 
respecto de los aspectos más específicos de la misma (entiéndase tipo de daño reparable, plazo de prescripción, forma de cómputo del mismo, régimen procesal para hacerla efectiva $)^{33}$ han ido apareciendo cada vez más cuerpos legislativos que establecen reglas aplicables al efecto. La más reciente, y de efectos difíciles de prever todavía, es la Ley 19.966, dictada en el contexto de la reforma global del sector salud impulsada por el Gobierno actual, que supone no solo una regulación minuciosa en cuanto a la naturaleza de los daños a indemnizar, sino también en cuanto a la prescripción de las acciones para hacer efectiva dicha responsabilidad y, por último, realizando con ello una innovación radical, a la imposición de la vía administrativa previa como condición para interponer un contencioso reparatorio en sede judicial.

Si bien la tesis de la doctrina nacional, hasta hace algún tiempo crecientemente aceptada por la jurisprudencia, conforme a la cual la responsabilidad del Estado -como persona jurídica de derecho público que es- se encuentra excluida de la aplicación de las reglas de responsabilidad regidas por el Código $\mathrm{Civil}^{34}$, es innegable concluir que, invocada que sea la aplicación de las normas de derecho público pertinentes, nuestros tribunales devanean en posiciones vacilantes y poco claras para resolver, bien la aplicación directa de tales normas de derecho público afirmando la responsabilidad estatal, o para construir sofisticadas y poco felices argumentaciones cuya intención última es liberar de responsabilidad al Estado.

En mi particular punto de vista, bastante ha contribuido a esa situación, el planteamiento conforme al cual en nuestro derecho la responsabilidad estatal sería imprescriptible, no porque exista alguna disposición normativa que así lo disponga, sino, por el contrario, por falta de una disposición de tal carácter que establezca positivamente dicha prescripción.

Tal circunstancia, netamente imputable a una omisión de nuestro legislador, ha venido a convertir la acción de responsabilidad del Estado

33 La precisión es necesaria atendido que tanto la Constitución Política de la República, en sus artículos 6, 7, 38 inciso $2^{\circ}$, como la Ley 18.575, Orgánica Constitucional de Bases Generales de la Administración del Estado, artículos $4^{\circ}$ y $42^{\circ}$, contienen disposiciones relativas a la responsabilidad del Estado, si bien, no se trata de normas que resuelvan los aspectos más específicos de la misma.

34 Confirmación de lo cual, junto a diversos fallos de responsabilidad estatal, viene a ser el pronunciamiento de la Excma. Corte Suprema del 5 de enero de 2005, en el recurso de casación de fondo rol N³640-2004, deducida por el Arzobispado de Santiago en contra de la sentencia que lo condenó civilmente por los abusos del presbítero Aguirre Ovalle, Analógicamente, encontrándose la Iglesia en el mismo estatuto jurídico del Estado frente a la aplicación de la legislación común, según establece el art. 547 inc $2^{\circ}$ del Código Civil, ratifica esta reciente jurisprudencia que las personas de derecho público responden al tenor de lo que dispongan sus propias leyes o estatutos que las rigen y no por las normas de responsabilidad extracontractual del título XXXV, Libro IV, del Código Civil. 
en un peligro permanente para la estabilidad de las cuentas públicas, cuyo conocimiento, incómodamente radicado en unos tribunales de justicia carentes de autonomía financiera, evidentemente dejan la cuestión entregada a merced de soluciones casuísticas, muchas veces con más componentes políticos que jurídicos.

\section{3) Análisis de algunas tendencias de la legislación y la JU- RISPRUDENCIA RECIENTES}

A la vista de la jurisprudencia de los últimos años, así como de alguna legislación sectorial administrativa ${ }^{35}$ aplicable a ciertas clases de responsabilidad estatal por su actividad (o inactividad) administrativa, pueden distinguirse tres grandes grupos de materias, con tratamientos bastante disímiles entre sí, resultando de esta falta de tratamiento unitario y orgánico, tal vez, la principal característica del régimen chileno de responsabilidad del Estado por hechos de la Administración en este tiempo, cual es, la falta de un fundamento racional y normativo único, que conlleva diversos problemas de inseguridad jurídica para los administrados y para todo el Estado de derecho.

Compartimos, a la hora de valorar los fallos que se comentan, lo sostenido por Romero, según quien, la falta de mecanismos para evitar la discriminación de los jueces en el ejercicio de la función jurisdiccional, es una característica de nuestro sistema judicial, que constituye, como queda en evidencia en esta como en otras materias, una abierta infracción al principio de igualdad ante la ley que garantiza el artículo $19 \mathrm{~N}^{\circ} 2$ de nuestra Constitución ${ }^{36}$.

\section{a) Responsabilidad estatal ocasionada en violaciones a los dere- chos humanos}

Si bien se trata de una materia en que, excepcionalmente, y contrariando la característica abstención del legislador a que se ha hecho mención más arriba, se han dictado leyes especiales para reparar y otor-

35 A modo meramente ejemplar: En la ley orgánica del Servicio Agrícola y Ganadero (Ley 18.755) artículos $5^{\circ}, 7^{\circ}$ letra j) y $47^{\circ}$; en la ley de protección agrícola (decreto ley 3557 de 1980) artículos $7^{\circ}$ y $8^{\circ}$; en la ley orgánica consticucional de Estados de Excepción (Ley 18.415) artículos 17, 19 y 20; en la ley de protección de datos personales (Ley 19.628) artículo 23; en la ley orgánica constitucional del Ministerio Público (Ley 19.640) artículo $5^{\circ}$.

36 Alejandro Romero Seguel, La jurisprudencia de los tribunales como fuente del derecho: una perspectiva procesal, Ed. Jurídica de Chile, Santiago, 2004, pp. 37-42 y 61-62. 
gar beneficios a las víctimas y a sus familiares ${ }^{37}$, que harían pensar que su análisis es más simple que en otras materias, la realidad judicial no lleva a la misma conclusión.

Los mecanismos de resarcimiento concebidos por el legislador, primero para reparar a los familiares de las víctimas de violaciones a los derechos humanos o de violencia política ${ }^{38}$ y luego a personas víctimas de torturas y prisión por razones políticas ${ }^{39}$, se construye sobre la base de pensiones pagaderas por el Estado.

El caso paradigmático con respecto a la compatibilidad entre la indemnización declarada judicialmente, y los beneficios reparatorios otorgados por la ley, es "Domic con Fisco" 40 , llevó a la Corte Suprema a acoger el recurso de casación en el fondo interpuesto por la defensa fiscal, revocando en consecuencia el fallo de la Corte de Apelaciones de La Serena que, confirmando el fallo de primera instancia, había acogido la demanda indemnizatoria.

Se trata de un precedente de particular importancia, atendidos los diversos tópicos relativos a la responsabilidad estatal que aborda, entre otros: la totalidad o integridad de la responsabilidad del Estado enfrentada a la compatibilidad de una indemnización judicial con los beneficios reparatorios otorgados por la Ley 19.123; la aplicación del código civil a la responsabilidad del Estado y, en especial, la regla de prescripción de 4 años para la responsabilidad extracontractual establecida en su art. 2332, e igualmente, supuesta dicha aplicación, la forma de computar tal plazo de la prescripción así como las eventuales interrupciones del mismo.

La sentencia aboga por una aplicación cabal de las normas sobre responsabilidad extracontractual del Código Civil, entre ellas, la norma de prescripción del art. 2332, cuando a falta de una regulación específica de derecho público, la cuestión quede sin regulación legal aplicable (considerandos $8^{\circ}$ y $9^{\circ}$ ).

Sobre el particular sostiene, que aunque la responsabilidad del Estado tenga un carácter especial y, en consecuencia, deba regirse por normas y principios de derecho público, no hay obstáculo en que, a falta de una regulación legal específica, y tratándose de una cuestión

37 La Ley 19.123, publicada en el Diario Oficial del 8.2.1992, establece una pensión de reparación a favor de los familiares de las víctimas de violaciones a los derechos humanos o de la violencia política. La Ley 19.992, publicada en el Diario Oficial el 24.12.2004, establece una pensión de reparación y otorga otros beneficios a prisioneros políticos y torturados.

38 Ley 19.123 de 1992.

39 Ley 19.992 de 2004.

40 Sentencia de la Corte Suprema del 15 de mayo de 2002, en casación de fondo rol 4753 2001, publicada en Gaceta Jurídica, N ${ }^{\circ}$ 263, año 2002. 
patrimonial, como es la reparación de daños, se apliquen las normas del derecho privado que versan sobre la prescripción de las acciones correspondientes (considerandos $1^{\circ}$ y $2^{\circ}$ ).

Sostiene además, que en virtud del art. 2497 del código civil ${ }^{41}$, no hay asidero normativo para sustentar una supuesta imprescriptibilidad de las acciones de perjuicios en contra del Estado, debiendo afirmarse, por el contrario, la procedencia de tal prescripción, conforme a la norma legal referida (considerandos $3^{\circ}$ y $4^{\circ}$ ).

Por último, en cuanto a compatibilidad de la pensión de reparación obtenida en virtud de la Ley 19.123, declara que, no obstante no existir una norma expresa que declare la incompatibilidad, la misma se deduce del contexto de la demanda, atendido el hecho que la indemnización que se pretende con la demanda tiene el mismo fundamento y una finalidad análoga que la pensión que se obtuvo, lo que las hace incompatibles entre sí (considerandos $16^{\circ}, 18^{\circ}$ y $19^{\circ}$ ).

Resulta esta sentencia, entonces, la negación cabal de cada una de las características de la responsabilidad del Estado afirmadas por nuestra doctrina, desde su sujeción a normas especiales de derecho público, pasando por la totalidad o integridad de la reparación, hasta llegar a la afirmación de que la prescripción de la acción reparatoria del Código Civil debe aplicarse con carácter supletorio a la responsabilidad del Estado a falta de otra norma legal expresa que la establezca. Como se ve, el razonamiento judicial dista mucho de poner la prioridad en la reparación de la víctima del daño, sino que se sitúa en la perspectiva de la protección del patrimonio del Estado, que jamás será la perspectiva correcta de tratamiento de la responsabilidad estatal conforme a las exigencias del principio de juridicidad.

\section{b) Responsabilidad asociada a las infracciones o delitos cometi- dos por agentes de la Administración}

La cuestión a resolver en estos casos, dice relación con el hecho que la pretensión judicial de obtener una condena por responsabilidad del Estado por las actuaciones antijurídicas de sus agentes no podría prosperar a menos que existiera un reconocimiento previo, por sentencia firme, que declare que la actuación del agente estatal ha sido contraria a derecho.

Se trata de casos en que la jurisprudencia acepta como fuente de responsabilidad estatal la responsabilidad personal del funcionario de

41 Establece que: "las reglas relativas a la prescripción se aplican igualmente a favor y en contra del Estado, de las iglesias, de las municipalidades, de los establecimientos y corporaciones nacionales, y de los individuos particulares que tienen la libre administración de lo suyo". 
la Administración (como fuente de responsabilidad estatal diversa a la falta de servicio), y en que como condición de su procedencia, se establece la necesidad de que tal falta haya sido declarada por una sentencia judicial firme.

La Corte Suprema, en fallo del año $2004^{42}$, en el caso "Meza Figueroa con Fisco", rechazó la casación de fondo del demandante en contra de la sentencia de la Corte de Apelaciones de Valparaíso que, revocando el fallo de primera instancia, declaró que la sola circunstancia de que haya sido un Carabinero quien conducía el furgón policial que atropelló a la cónyuge del demandante, no basta para dar por sentada la responsabilidad del Estado, mientras no exista sentencia firme que declare la culpabilidad del funcionario estatal (considerando $12^{\circ}$ ).

La complicación práctica que ocasiona este razonar de los jueces, además del error doctrinal que supone, se traduce en el riesgo de prescripción de las acciones indemnizatorias, en estos casos totalmente reconducidas por los jueces y por los abogados actuantes en el pleito, a las normas de responsabilidad extracontractual por el hecho de los terceros que se tienen bajo cuidado o dependencia (artículos 2320 y 2322 del código civil), a menos que se tome la precaución de no esperar para interponer la acción a que quede afinado el proceso penal o infraccional que corresponda según la naturaleza de los hechos que ocasionan el daño.

Prueba del error doctrinal señalado, aunque posteriormente corregido por la Corte Suprema, lo constituye el fallo de primera instancia dictado por el juez de San Antonio, confirmado en la Corte de Apelaciones, en el caso "Moyano Pavez con Fisco" 43 que, habiendo condenado a los carabineros que, por violencia innecesaria en ejercicio de sus funciones, causaron la muerte del menor Moyano Jara, exculpó de responsabilidad patrimonial al Estado afirmando que, conforme las normas del Código Civil, no se lo podía hacer responder del hecho impropio de sus dependientes que él no pudo prever e impedir.

Si bien la Corte Suprema no rechaza la aplicación de las normas del Código Civil a la responsabilidad del Estado, ni afirma en su lugar que lo que corresponde es aplicar las normas de derecho público, sí advierte la flagrante injusticia que resultaba de liberar de toda responsabilidad al Estado, una vez probado que los funcionarios de su dependencia son responsables del homicidio del menor Moyano Jara, y ante tal circunstancia afirma la responsabilidad solidaria del Estado junto a los autores materiales del daño, afirmando que existe una pluralidad de sujetos

42 Casación de Fondo rol N $\mathrm{N}^{\circ}$ 4548-2003, sentencia de la Corte Suprema del 13.07.2004.

43 Casación de Fondo rol N $\mathrm{N}^{\circ}$ 4961-2003, sentencia de la Corte Suprema del 03.05.2004. 
pasivos en dicha responsabilidad, conforme al artículo 38 inciso $2^{\circ}$ de la Constitución (considerandos $7^{\circ}$ y $8^{\circ}$ ).

\section{c) Responsabilidad por casos de falta u omisión de servicio}

Es responsabilidad por falta de servicio, no falta "del" servicio, y en ese sentido, obviamente, no se apunta a que debe buscarse una razón subjetiva de imputación del daño en un agente público. Se trata, bajo ese punto de vista, de una especie de responsabilidad de raíz objetiva, en cuanto sin necesidad de acreditar la intencionalidad del agente público, basta con acreditar una de 3 cosas posibles ${ }^{44}$ : 1) la omisión de funcionamiento del servicio; 2) el funcionamiento defectuoso; y 3) el funcionamiento tardío. Comprobado que sea uno de estos supuestos, acreditado el daño y la relación causal, el organismo debe reparar.

Se trata de una tipología especial de responsabilidad estatal que se da, por razón legislativa, en dos ámbitos bien definidos de la organización administrativa del Estado chileno: en materia municipal (por el art. 141 de la Ley 18.695) y en la actividad de los servicios públicos (art. 42 de la Ley 18.575).

En materia municipal, tal vez, es el ámbito donde con mayor claridad se ha dado la aplicación judicial del carácter objetivo de la responsabilidad pública, si bien, con la especialidad de que su carácter objetivo queda condicionado a la posibilidad de comprobar un deber positivo de actuación por parte de la Municipalidad, que en general debe encontrarse establecido por la ley.

Desde "Tirado con Municipalidad de La Reina" (1981) ${ }^{45}$, pasando por "Villegas con Municipalidad de Providencia" $(1989)^{46}$, hasta los más recientes "Palma González con Municipalidad de Concepción" (2002) ${ }^{47}$ y "Vera Castro y otros con Municipalidad de Viña del Mar" $(2003)^{48}$ la jurisprudencia ha sido constante en afirmar que, una vez constatada la responsabilidad legal del municipio de prestar y mantener un servicio local determinado, verificadas que sean las malas condiciones de prestación del mismo y el daño sufrido por un particular a consecuencia de las mismas, el municipio debe indemnizar.

En materia de la responsabilidad de servicios públicos y, en particular, respecto de los servicios de salud, se está imponiendo por la

\footnotetext{
Cfr. Ricardo SANHueza Acosta, Responsabilidad patrimonial... op. cit., p. 168.

Cfr. Eduardo Soto KLoss, Derecho Administrativo... op. cit., pp. 328-345.

Cfr. Idem, pp. 345-354.

Casación de Fondo rol N ${ }^{\circ}$ 1104-2002, sentencia de la Corte Suprema del 7.5.2002.

Casación de Fondo rol N $\mathrm{N}^{\circ}$ 921-2002, sentencia de la Corte Suprema del 24.6.2003.
} 
vía legislativa una auténtica revolución en materia de responsabilidad estatal en Chile.

En primer lugar, porque tanto en la Ley 19.937 como en la Ley 19.966, ambas del año 2004, que implementan una sustancial reforma del sector sanitario nacional, se establecen normas específicas:

$1^{\circ}$ en cuanto a la naturaleza de la responsabilidad (art. 38 de la Ley 19.966, es responsabilidad orgánica por falta de servicio, superando así la tentación de aplicar las categorías del Código Civil, como ocurrió hasta hace poco "Oviedo Pérez con Servicio de Salud de Talcahuano" $\left.{ }^{49}\right)$. La necesidad de dolo o negligencia del funcionario será requisito solo para que los órganos de la administración ejerzan la acción de repetición en contra del funcionario causante del daño;

$2^{\circ}$ en cuanto al tipo de daño a reparar (art. 41 establece indemnización por daño moral, que será fijada en atención a la gravedad del daño y a la alteración de las condiciones de existencia del afectado);

$3^{\circ}$ en cuanto a exenciones de responsabilidad (art. 41 inciso $2^{\circ}$ : no serán indemnizables los daños que se deriven de hechos o circunstancias que no se hubieren podido prever o evitar según el estado de los conocimientos de la ciencia o de la técnica existentes al momento de producirse aquellos $)^{50}$; o bien,

$4^{\circ}$ en cuanto a la prescripción, con la regla expresa del art. 40 que establece la prescripción en 4 años contados desde la acción u omisión.

A lo anterior se suman dos cuestiones de especial importancia, una sustantiva y otra de índole procesal.

En lo sustantivo, la Ley 19.966 introduce un sistema de garantías explícitas de salud, que remite a Decretos que establecerán los términos concretos de tales garantías, en cuanto al acceso a las prestaciones, a la calidad de las mismas, a su oportunidad y a la protección financiera de los usuarios. En cuanto a tales garantías concretas, que se fijarán por decreto y constituyen derechos para los usuarios, el legislador dispone que se tendrá en consideración los recursos físicos, humanos y presupuestarios disponibles (art. $3^{\circ}$ de la Ley 19.966). También se establece que se entenderá que no hay incumplimiento de la garantía de oportunidad en caso de caso fortuito, fuerza mayor o causa imputable al beneficiario.

Por último, la Ley 19.937, en su artículo $1^{\circ}$, dispone que el Ministerio de Salud establecerá los estándares mínimos que deberán cumplir

49 Casación de fondo rol 3665-2000, sentencia de Corte Suprema del 24.1.2002.

50 Cfr. artículo 141.1 de la ley $30 / / 1992$ de la ley española sobre LRJ-PAC. 
los prestadores institucionales de salud entre los que se incluyen normas sobre condiciones sanitarias, seguridad de instalaciones y equipos, aplicación de técnicas y tecnologías, protocolos de atención, competencias de los recursos humanos, y toda materia que incida en la seguridad de las prestaciones.

Lo anterior supone que el legislador remite a la propia administración sanitaria la definición de las normas generales, en contraste con las cuales se podrá comprobar o no una falta de servicio que dé origen a la responsabilidad por los daños ocasionados a los usuarios. La jurisprudencia ya había incursionado en esta forma de tratar la responsabilidad de los servicios de salud, en "Villar Pavez con Servicio de Salud Area Hospitalaria Central" (1986) ${ }^{51}$, afirmando que hubo falta de servicio porque el Servicio de Salud no demostró haber cumplido con los protocolos de seguridad de funcionamiento de los bancos de sangre.

Por último, en el aspecto procesal, una novedad absoluta en el derecho nacional en lo que se refiere a las reglas para proceder judicialmente a solicitar una indemnización por daños ocasionados por el Estado. El artículo 43 de la Ley 19.966 impone un novedoso mecanismo de solución de controversias por la responsabilidad en las prestaciones de salud, consistente en un sistema de mediación forzosa que condiciona la posibilidad de ejercer las acciones jurisdiccionales de reparación contra los prestadores institucionales públicos, a que el interesado previamente someta su reclamo a un procedimiento de mediación ante el Consejo de Defensa del Estado.

Es una fórmula curiosa tanto en el derecho chileno, en que no existe ningún otro caso de impedimento legal para acudir a la tutela judicial reparatoria en contra del Estado sin haber cumplido con este requisito, como también a nivel comparado, puesto que, en estricto sentido, tampoco constituye un caso de vía administrativa previa, atendido que de esa instancia de mediación solo pueden derivarse dos efectos posibles, que se arribe a una transacción extrajudicial que evite un juicio posterior o, en su caso, que no se llegue a ninguna solución y en ese caso el particular podrá ejercer su acción jurisdiccional libremente (el art. 45 de la Ley 19.966 establece que se suspende el plazo de prescripción de las acciones civiles y penales mientras dura la mediación).

Con ojos críticos, la lectura que se puede hacer de esta legislación resulta muy poco alagüeña. En buenas cuentas, pareciera ser que el propio Estado que se ha resistido a crear una jurisdicción especializada contencioso administrativa, confiado en que los tribunales ordinarios ofrecen una vía de solución justa y adecuada a la necesidad de resolver

51 Cfr. Eduardo Soto KLoss, Derecho Administrativo... op. cit., pp. 372-384. 
las controversias entre la administración y los ciudadanos, cambia de opinión cuando se trata de un tema que ha ido cobrando interés creciente por la cuantía y por la mayor frecuencia de las causas que llegan al conocimiento de los tribunales ordinarios.

Hecha la salvedad de estos tres grupos de materias que, sea por tratamiento de los jueces o por regulación legislativa expresa, deben analizarse bajo la perspectiva de tales peculiaridades, la disyuntiva sigue siendo cuál es el régimen de responsabilidad estatal generalmente aplicable, esto es, un régimen que parte del supuesto de la base constitucional de dicha responsabilidad u otro que se afana por reducirlo a las categorías del derecho civil, básicamente por razones de seguridad jurídica, esto es, de tener un derecho positivo que permita a los jueces fundar sus fallos y a la administración invocar algunas normas positivas que limiten una supuesta responsabilidad objetiva por todos los daños que ocasione su actuación (incluso si no hay antijuridicidad en la actuación).

Desde luego, mi convicción por la primera de las posiciones, aun contrariando el parecer de la doctrina civilista ${ }^{52}$, es que, en general, la responsabilidad estatal tiene su origen en la Constitución y en la subordinación a derecho que esta impone a los órganos que ejercen los poderes públicos. La tentación, sea por razones de justicia, o por otras menos encomiables que solo buscan con ello dificultar la configuración de la responsabilidad del Estado, de reconducir otra vez la responsabilidad a la legislación civil, no deja de tener en sí el grave peligro de desfigurar tal instituto, al extremo de hacerlo inoperante y de destruir, acto seguido, una de las instituciones básicas de todo Estado de Derecho.

El peligro de seguir analizando la responsabilidad del Estado bajo el prisma de las normas del derecho civil, con seguridad, significará, salvo en los casos en que el legislador ha hecho un tratamiento expreso de la cuestión, un peligroso retroceso a la jurisprudencia del caso Granja con Fisco del año 1938, que junto con aceptar la aplicación del código civil en aquellos supuestos de actividad material de la administración denominados de gestión, establecía como regla general la imposibilidad de fallar la responsabilidad estatal tratándose de actos de autoridad o poder, a menos que una ley expresa así lo estableciera, resultando así, que la responsabilidad para este amplio campo de supuestos de abusos y daños ocasionados a los particulares solo sería excepcionalmente indemnizado.

52 Cfr. Fernando Pantaleón Prieto, "Los anteojos del civilista: hacia una revisión del régimen de responsabilidad patrimonial de las administraciones públicas", en Revista de Derecho del CDE, $\mathrm{N}^{\circ}$ 2, 2000, pp. 79-95. Cfr. también Hernán Corral TAlciani, Lecciones de responsabilidad civil extracontractual, Edit. Jurídica de Chile, Santiago, 2004, pp. 298-311. 
Obviamente, volver a esa situación, lleva a concluir que nuestro ordenamiento jurídico no ha tenido realmente un gran avance en la protección de los derechos de los administrados.

\section{4) Conclusión}

El análisis de la jurisprudencia y de la legislación chilena más recientes, llevan a sostener que la falta de unidad y de consistencia en materia de responsabilidad del Estado, según el tipo de materia administrativa de que se trate, impiden afirmar que exista en Chile un sistema consolidado que sea garantía suficiente para los administrados de que los daños que les ocasionen los órganos de la administración en el ejercicio de sus funciones vayan a ser efectivamente reparados.

Si bien nuestra Constitución Política y la legislación que la complementa, han establecido expresamente la responsabilidad del Estado por los daños que causen los órganos de la Administración en el ejercicio de sus funciones a alguien que no está jurídicamente obligado a soportarlo ${ }^{53}$, como una consecuencia de las exigencias del Estado de derecho, no es menos cierto que la realidad práctica de aplicación de esas normas dista mucho de ser consistente con un auténtico sistema de garantía para los administrados.

Posiblemente, no poca responsabilidad de ello tienen los propios tribunales de justicia llamados a conocer de las demandas indemnizatorias en contra del Estado, que haciendo más caso a los argumentos de interés esgrimidos por la Defensa Judicial Fiscal, han retrocedido a posiciones doctrinales que, por un tiempo, parecieron finalmente superadas con el advenimiento de la Constitución de 1980.

Se ve que la lucha por el Estado de derecho y por las garantías de los administrados frente a los abusos de la Administración, aún no ha llegado entre nosotros a un grado de madurez suficiente que permita superar los dogmas preconstitucionales, según los cuales, el gobernante siempre actúa a favor de sus súbditos, y los daños que estos sufren en sus bienes y derechos derivados de la acción estatal son un sacrificio menor comparado con el beneficio general que reciben del aparato público, lo que justifica que la responsabilidad del Estado sea considerada con criterios de excepción y no como una regla general.

53. Cfr. Eduardo Soto KLoss, Derecho Administrativo... op, cit, pp. 307-308. 